\author{
Olga Boginskaya* \\ Irkutsk National Research Technical University, Russia \\ boginskayaoa@istu.edu
}

\title{
THE SIMPLIFICATION OF JURY INSTRUCTIONS: LEGAL-LAY INTERACTIONS IN JURY TRIALS
}

\section{Abstract}

The paper presents an empirical contribution to the area of comprehension of jury instructions, which have been intensively investigated in recent decades. By conducting a discursive analysis of the corpus of pattern jury instructions, this article discusses explanatory strategies that contribute to efficient communication in the courtroom. These explanatory strategies - definition, description, exemplification, and metaphorization - are typically employed with the aim of improving the comprehensibility of jury instructions. A paraphrasing experiment was conducted to assess the layperson's ability to understand jury instructions before and after employing the explanatory strategies. Forty-four native Englishspeaking undergraduate and postgraduate students were asked to paraphrase pattern jury instructions containing the legal concepts "preponderance of evidence" and "circumstantial evidence". Interpretation errors were evaluated to assess comprehension results. The results underpin the paper's central argument that the explanatory strategies can improve the comprehensibility of legal texts indicating that efforts should be undertaken to explain abstract legal concepts to a lay audience. The pedagogical implications on the explanatory structures are also drawn.

\section{Key words}

jury instruction, explanatory strategy, comprehension, legal discourse, lay audience, knowledge asymmetry.

\footnotetext{
* Corresponding address: Olga Boginskaya, Institute of Linguistics and Cross-cultural Communication, Irkutsk National Research Technical University, Lermontov str. 83, 664074, Irkutsk, Russia.
} 


\section{INTRODUCTION}

The jury trial involves two categories of actors: legal experts trained in the field of law, and laypersons who have no knowledge of law. This categorization illustrates the asymmetrical relationship that exists in the courtroom. Knowledge asymmetries should be considered from a speaker-audience perspective, taking into account legal knowledge transfer from the formal legal language to the language of common citizens (Roelcke, 2018: 21). As Zethsen (2009: 806) points out, the knowledge factor "centers around the ability of comprehension of the target group, i.e. the target group's general ability to understand a text, its level of general background knowledge or its level of expertise (or lack of) in connection with a specific subject [...]. Typical intralingual translations instigated by the parameter of knowledge (explanatory translations) are typically of the expert-tolayman kind".

A large pool of research is available on expert-lay interactions (Anesa, 2016; Ciapuscio, 2003; Gotti, 2014; Heffer, 2005; Krapivkina, 2017; Roelcke, 2018; Tiersma \& Curtis, 2008; Turnbull, 2018). For example, Anesa (2016) sought to describe the peculiarities of expert-lay interaction and identify explanatory structures which contribute to the popularization of legal information through the analysis of a corpus of threads drawn from law forums. Ciapuscio (2003) described one explanatory strategy - reformulation - as efforts made by the participants to the communication act in order to produce expressions more suitable to the interlocutor's level of comprehension. Turnbull (2018: 203-204) described illustrations and explanations as explanatory strategies employed with the intention to present specialized knowledge. As Gotti (2014) holds, thematization and denomination are the main explanatory procedures which can help communicate expert knowledge to laypeople. Little attention has, however, been devoted to research into comprehensibility of jury instructions, and explanatory strategies have barely been treated or analyzed from their perspective (Anesa, 2012; Tiersma, 2010). The current study was thus motivated by the lack of explicit guidance for interacting with lay persons in the courtroom, and challenges faced by jury members in attempting to understand elusive legal concepts. This article aims to identify and analyze diverse explanatory strategies used by judges in jury instructions and assess comprehension difficulties experienced by laypeople before and after employing these strategies in the instructive texts. An assessment is based on the results of a paraphrasing experiment involving native Englishspeaking undergraduate and postgraduate students.

This article opens with a presentation of the most relevant theoretical background of conceptions of legal-lay interactions in jury trials drawing attention to the ways the solutions to legal language comprehensibility problems have been suggested by other researchers. In Section 3, the research objectives, the corpus, including the corpus selection criteria, and the procedures employed to analyze explanatory strategies and comprehensibility issues are described. Following that, 
the findings are discussed. The main explanatory strategies found in the corpus are analyzed through the exemplification, and experiment results are assessed. In Section 5, some recommendations regarding the pedagogical implications are offered. Finally, in Section 6, conclusions on the explanatory structures are drawn and further research avenues are outlined.

\section{LITERATURE REVIEW}

To start with, it is worth inquiring into the studies of legal-lay interactions in linguistic literature - in itself, not very extensive. Previous research has shown that legal professionals and jurors use different types of knowledge (professional knowledge versus everyday knowledge), which gives rise to a complex dialogue based on the subjective reconstruction of phenomenological experience, on the one hand, and logical principles and legal rules, on the other hand (Anesa, 2009, 2016; Baguley, McKimmie, \& Masser, 2017; Charrow \& Charrow, 1979; Diamond \& Levi, 1996; Frank \& Applegate, 1998; Heffer, 2005; Krapivkina, Kolesnikova, Borisovskaya, \& Taranova, 2019; Nickerson, 1999; Tiersma \& Curtis, 2008; Wiener, Pritchard, \& Weston, 1995).

Heffer (2005) describes the judge's role as legal guide to the jury, explores variation among judges in the delivery of instructions, and raises the question as to whether comprehension of jury instructions might be improved through linguistic accommodation or standardized simplification of written texts. He claims that lawyers

"have been taught to follow 'paradigmatic' legal principles and procedures, and are well aware of the contribution an evidential point might make to their logic-based legal case. At the same time, they are equally well aware of the need to communicate with and persuade a group of lay people (the jurors) who are unlikely to reason in a paradigmatic fashion with respect to evidence detailing the crime narrative at the heart of the case." (Heffer, 2005: 15).

The communicative asymmetry creates a discoursal tension which is manifested in both the macrolinguistic structures of the courtroom genres, including jury instructions, and in the microlinguistic choices of the legal professionals. Professional training contributes to mutual understanding between members of the same discourse community. However, lay participants will inevitably not have the same training and understanding. Therefore, legal professionals are forced to employ discursive strategies that facilitate comprehension on the part of a lay audience.

As Anesa (2016: 83) points out, "lawyers do not abandon the need to promote their professionalism, expertise and qualifications, but navigate these characteristics and their temporary mitigation in order to provide more informal, simplified expressions deemed more appropriate in relation to user needs". Jury 
members come into court as expert triers of fact rather than experts in law. Yet the grounds for their decisions are expertus, or known by experience, their experience of everyday life. Bruner (1991) calls it a folk psychology - a sense of the world which is common to the community, a system by which people organize their experience. In most cultures, the organizing principle of this folk psychology is narrative in nature: "Folk psychology is about human agents doing things on the basis of their beliefs and desires, striving for goals, meeting obstacles which they best or which best them, all of this extended over time" (Bruner, 1991: 2). Jury members bring common-sense and lay experience rather than legal expertise into the courtroom. In other words, they use a narrative rather than a paradigmatic mode of thinking (Heffer, 2005).

In recent decades, lawyers and linguists have paid increasing attention to the issue of jury instructions. Pattern jury instructions began to appear in the 1930s and are now commonly used throughout the United States (Tiersma \& Curtis, 2008). Many US states have drafted their instructions user-friendly, employing principles intended to make these legal texts more comprehensible. Of interest is an attempt made by California, which revised all of its jury instructions. New plain language jury instructions created in the USA explain legal concepts by means of examples.

The earliest strategy used to facilitate the comprehensibility of jury instructions is linguistic simplification (Charrow \& Charrow, 1979), which involves the use of more common words, short simple sentences, active sentences and logical structures. Buchanan, Pryor, Taylor, and Strawn (1978) exposed research participants to pattern instructions and found a number of areas where jurors had experienced comprehension difficulties. The research conducted by Charrow and Charrow (1979) showed that the simplification methods used improved jurors' comprehension. In their work they described their study of selected California jury instructions starting from three hypotheses: (1) that pattern jury instructions are not well understood by the average juror; (2) that certain linguistic constructions are responsible for this incomprehensibility; and (3) that if the complex linguistic constructions are appropriately altered, comprehension should improve. In their experiment, Charrow and Charrow (1979) explained the meaning of technical terms and replaced problematic linguistic constructions with simpler ones, which improved the comprehensibility of jury instructions.

Several other studies (Diamond \& Levi, 1996; Elwork, Sales, \& Alfini, 1977; Frank \& Applegate, 1998; Imwinkeiried \& Schwed, 1987; Wiener et al., 1995) also demonstrate significant improvements in comprehension when abstract and legalistic words were avoided. Elwork et al. (1977) sought to improve jurors' ability to comprehend instructions using psycholinguistic principles, i.e. rewriting jury instructions. Imwinkeiried and Schwed (1987) described four psycholinguistic methods which can improve the comprehensibility of instructions: substitution of abstract and legalistic words with the words of everyday language, sentence simplification, sentence length reduction, and proper 
text organization. An experiment conducted by Wiener et al. (1995) showed that rewritten instructions containing lay concepts and syntactically simple structures were more comprehensible to the mock jurors. Tiersma and Curtis (2008) compared comprehension of the new civil instruction on circumstantial evidence with comprehension of the old circumstantial evidence instruction and concluded that the new instruction is more effective than the old one at overcoming the common understanding of "circumstantial evidence" as "weak evidence." Zethsen (2009) experimentally identified the following strategies intended to improve the comprehensibility of jury instructions: paraphrasing, restructuring, and simplification. Cacchiani (2018: 192) defined these strategies as processes "whereby exclusive expertise translates into intelligible knowledge". Baguley, McKimmie, and Masser (2019) reviewed methods used to make inferences about jurors' application of instructions, and recommended ways to improve them in future research to enable researchers to draw more precise conclusions about the quality of jurors' decision-making.

\section{THE CURRENT STUDY}

\subsection{Research questions}

This paper analyzes explanatory strategies in a specific discourse type: judge-jury interactions in the courtroom. Assuming that explanatory strategies constitute an identifiable field of study within the broader field of discourse studies, this paper is linguistic research on asymmetrical discursive interactions. It sets out to investigate the explanatory strategies employed in pattern jury instructions to ensure the accessibility and comprehensibility of the information provided by the judge. Jury instructions are complex, and jurors have difficulty comprehending them, which is problematic because jurors can only apply instructions to the extent they understand them (Baguley et al., 2017). The paper also aims to identify linguistic features of jury instructions which make them difficult to process and assess comprehension difficulties experienced by laypeople before and after employing explanatory strategies in the instructive texts. Thus, considering the crucial role that explanatory strategies assume in legal-lay discourse, including jury instructions, the following research questions were formulated to guide this analysis:

(1) What explanatory strategies are used to communicate legal information to jurors?

(2) Which of these explanatory strategies are most commonly used in the corpus? 
(3) Which linguistic features interfere with or reduce comprehension of jury instructions?

(4) To what extent do the explanatory strategies improve the comprehensibility of jury instructions?

The paper also aims to demonstrate applications of the findings of the study for ESP pedagogy.

\subsection{Corpus design}

To meet the aforementioned objectives, three sub-corpora including jury instructions derived from the websites of US courts, namely the California courts, the Eastern District Court of Michigan, and the District court of South Carolina, were analyzed. All the instructions date back to the period between 2003 and 2018 as the aim was to focus on recent texts which are synchronically comparable. The size of the corpus totaled 71,659 words distributed throughout 27 texts. Table 1 summarizes the size of each sub-corpus.

\begin{tabular}{|l|l|l|}
\hline SUB-CORPUS & JURY INSTRUCTIONS & $\begin{array}{l}\text { TOTAL WORD COUNT OF ALL } \\
\text { JURY INSTRUCTIONS }\end{array}$ \\
\hline SB1 $^{1}$ & 9 & 27,667 \\
\hline SB2 $^{2}$ & 9 & 16,959 \\
\hline SB3 $^{3}$ & 9 & 27,033 \\
\hline Total & $\mathbf{2 7}$ & $\mathbf{7 1 , 6 5 9}$ \\
\hline
\end{tabular}

Table 1. Corpus composition

To compile the corpus for this study, nine pattern jury instructions per sub-corpus were selected and analyzed in terms of the explanatory strategies used to improve the comprehensibility of legal concepts. The jury instructions were selected based on the following criteria:

(1) the texts were required to contain explanatory strategies (old jury instructions ${ }^{4}$ which are not user-friendly for jurors were thereby excluded);

(2) the texts were required to contain legal concepts which are difficult for jurors to grasp.

\footnotetext{
${ }^{1}$ Official website of the California courts: http://www.courtinfo.ca.gov/jury/juryinst.htm

2 Official website of the Eastern District Court of Michigan: http://www.mied.uscourts.gov

3 Official website of the District court of South Carolina: http://www.scd.uscourts.gov/

${ }^{4}$ Jury instructions which have not yet been revised by the Judicial Councils.
} 
Instructions that met these criteria were shortlisted and selected to build the corpus. PDF or Word files of the selected instructions were downloaded from the court websites. The US courts were randomly selected from those which were among the first US judicial bodies to draft pattern jury instructions taking their comprehensibility into account. 5 Pattern jury instructions have been used in California, Michigan and South Carolina courts since 2003. They are available for specific areas of law, such as crimes against property, employment, medical, and products liability. Given at the end of the trial, they instruct the jury on the relevant law, provide them with general instructions about their behavior and help to deliver verdicts because they describe the procedures jurors should follow to evaluate the evidence (Lieberman, 2009). Because the jury instructions explain relevant law, they are written in legal language which has long been recognized as difficult for laypeople (Tiersma, 1999), and present special difficulties because of their linguistic complexity. Thus, the communicative efficiency of pattern jury instructions is crucial to a fair trial and explains the need for studies aimed at the improvement of their comprehensibility. The corpus built may be used to confirm the presence of explanatory strategies when legal knowledge is transferred to a lay audience. It also provides authentic examples to explore how explanatory strategies may be used to make jury instructions user-friendly for jurors.

\subsection{Research methodology}

In order to go beyond a mere list of explanatory strategies typically employed in jury instructions, the present study applied analytical and experimental methods. Two types of analyses are provided in the first part of this paper (subsection 4.1.). Special attention was devoted to the identification of explanatory strategies which are used to connect old and new legal knowledge for simplification purposes and description of their functions in legal-lay interactions. A quantitative analysis identified the frequency of explanatory strategies used in the corpus. The next step in the quantitative analysis was to identify verbs employed to define legal concepts. This means that the average frequency of occurrences of verbs introducing definitions (in this paper, an 'average frequency' is defined as the total number of times a verb occurs in all the jury instructions included into the corpus) was identified. The verbs and the frequency of their occurrences were summarized in a table format as illustrated in Table 2. In addition to analyzing the verbs introducing definitions, the types of description and exemplification structures and the average frequency of their occurrences in the corpus were also identified. The results are presented in Tables 3 and 4 . The examples quoted in this paper are

\footnotetext{
5 The information about these courts is based on the conclusions drawn by Tiersma (2010) and McCarthy (2003).
} 
coded by indicating the abbreviated name of the sub-corpus followed by its number (e.g. SB 1).

The second part of this paper (subsection 4.2.) describes the results of a paraphrasing exercise. For the experiment on comprehensibility, we used two legal concepts "preponderance of evidence" and "circumstantial evidence". The experiment involved forty-four native English-speaking undergraduate and postgraduate students. The reason why university students were chosen was that according to Rose and Ogloff (2001), when exposed to the same instructions, university students' comprehension is similar to actual jurors. Similar to jurors, university students find it difficult to understand jury instructions containing elusive legal concepts. None of them had any legal training and none had served on a jury. Paraphrasing was based on the method suggested by Charrow and Charrow (1979). The researchers had previously recorded fourteen California instructions on audio tape. They played the tape twice to each subject. Participants were then asked to paraphrase the jury instructions; these paraphrases were tape-recorded and analyzed to determine how many segments were correctly paraphrased by the study participants. In the present study, two jury instructions were recorded and played twice to each of 44 participants who were then asked to paraphrase the segments of the instructions which contained the legal concepts "preponderance of evidence" and "circumstantial evidence". The experiment was followed by an analysis of the paraphrases intended to reveal the accuracy of comprehension of the legal concepts. Next, the explanations of the legal concepts "preponderance of evidence" and "circumstantial evidence" provided by the participants before and after employing the explanatory strategies were compared. A survey on the linguistic features that impede the comprehension of jury instructions was also conducted in the present study. It consisted of questions on the types of comprehension difficulties faced (see the Appendix). The same research participants were involved, and they each filled out the same survey. They then marked those features that impeded their comprehension of the instructions. Their answers were analyzed and then summarized in a table format as illustrated in Table 7.

\section{RESULTS AND DISCUSSION}

\subsection{Explanatory strategies}

This subsection overviews the main explanatory strategies employed in the corpus. The findings reveal that the most common strategies used in jury instructions with the intention of explaining elusive legal concepts and making legal information comprehensible to a lay audience are (1) definition, (2) description, (3) exemplification, and (4) metaphorization. 


\subsubsection{Definition}

One of the explanatory strategies used by lawyers to improve clarity of highly technical terms belonging to the legal vocabulary are definitions. Interestingly, the definitional functions are different in professional and hybrid discursive practices: while in professional discourse definition is employed "when a new term is coined, or new meanings are attached to existing words within the discipline" (Gotti, 2014: 18), in expert-lay interactions it is used with the intention of explaining the meaning of all technical terms (Calsamiglia \& van Dijk, 2004) and ensuring the comprehensibility of expert discourse, which is determined by the speaker's ability to switch from professional language to the lay one.

It is well-known that a great number of legal words are unfamiliar to the jury or have different meanings in General English (e.g. murder, intent, negligence, bribe, aggravation, mitigation, burglary, assault, etc.). For example, in General English "burglary" means "breaking into a house", while in Legal English "burglary" is defined as "breaking the law" 6 . These legal words often appear in jury instructions and need to be explained due to their incomprehensibility. Here are two extracts from the jury instructions which contain definitions of the commonly used legal terms:

[1] The indictment is simply the description of the charge made by the government against the defendant; it is not evidence of anything. (SB 1)

[2] Circumstantial evidence is evidence that, if found to be true, proves a fact from which an inference of the existence of another fact may be drawn. A factual inference is a deduction that may logically and reasonably be drawn from one or more facts established by the evidence. (SB 2)

"Indictment" and "circumstantial evidence" are explained by providing definitions which express the essential nature of the legal concepts and are used to discursively represent knowledge about the unknown words or word combinations.

[3] Jeopardy is commonly defined as referring to an objective state of danger, not to a subjective feeling of fear. (SB 3)

The judge tries to eliminate any possible misunderstanding regarding the meaning of "jeopardy" by providing its technical definition.

The findings of the present study reveal that the main structure of definitions in the corpus is Legal term + Definition, introduced by the verbs "be", "mean", "include", or "be defined":

[4] An agent is one who is authorized to act on behalf of or in the place of another. (SB 3)

\footnotetext{
${ }^{6}$ Legal dictionary. Retrieved from http://legal-dictionary.thefreedictionary.com
} 
[5] "Embezzle" means the deliberate taking or retaining of the property of another with the intent to deprive the owner of its use or benefit by a person who has lawfully come into the possession of the property. (SB 3)

[6] Misapplication includes the wrongful taking or use of the money or property of the Indian tribal organization, by its agent for his or her own benefit. (SB 3)

[7] Actual possession is defined as physical control over property. (SB 2)

As shown in Table 2, "be" is the most commonly used of the verbs introducing definitions of legal concepts in the corpus.

\begin{tabular}{|l|c|}
\hline VERB & FREQUENCY OF OCCURRENCES, \% \\
\hline to be & 33 \\
\hline to mean & 24 \\
\hline to indicate & 18 \\
\hline to include & 15 \\
\hline to be defined & 10 \\
\hline
\end{tabular}

Table 2. Distribution of the verbs introducing definitions in jury instructions

The definition often contains the metalinguistic units such as "a sort of", "a kind of", or "like" that indicate the semantic approximation of the technical term. These metalinguistic tools occur only in legal-lay interactions, since the approximation is incompatible with the nature of legal texts. The following example illustrates this type of metalinguistic process:

[8] A conspiracy is an agreement between two or more persons to join together to accomplish the unlawful purpose. It is a kind of partnership in crime in which each member becomes the agent of every other member. (SB 3)

\subsubsection{Description}

Along with definitions, legal professionals often describe legal concepts without delving into their theorization because what laypeople need is an understanding of a concept, rather than its abstract definition. Being enlarged versions of definitions, descriptions used to explain expert knowledge by relating it to common knowledge have simpler structures (Anesa, 2016; Ciapuscio, 2003). A concept that is defined can be explained through a description more elaborately. The process is illustrated in the following example.

[9] Proof beyond a reasonable doubt is proof that leaves you firmly convinced of the defendant's guilt. There are very few things in this world that we know with absolute certainty, and in criminal cases the law does not require proof that overcomes every possible doubt. If, based on your consideration of the evidence, you are firmly convinced that the 
defendant is guilty of the crime charged, you must find him guilty. If, on the other hand, you think there is a real possibility that he is not guilty, you must give him the benefit of the doubt and find him not guilty. (SB 3)

In order to explain the legal concept, the judge describes it relating to the shared experience and further actions of the jury. The description provides a set of characteristics by which the legal phenomenon can be recognized. As distinct from definitions, descriptions are narrative rather than paradigmatic. They may be limited to a clause or extend throughout large paragraphs. Consider the following example explaining the nature of "evidence" through a description which extends throughout the paragraph consisting of six sentences:

[10] The evidence in this case includes only what the witnesses said while they were testifying under oath; the exhibits that I allowed into evidence. Nothing else is evidence. The lawyers' statements and arguments are not evidence. Their questions and objections are not evidence. My legal rulings are not evidence. And my comments and questions are not evidence. (SB 2)

In the above example, the description provides structural and dynamic information in terms of properties and functions of the phenomenon. The nature of evidence is explained by including and excluding information that can be considered to be evidence in the case.

Interesting for the present analysis is that sometimes descriptions are offered before the legal concepts have been introduced. The following example illustrates the case:

[11] When I tell you that a party must prove something, I mean that the party must persuade you, by the evidence presented in court, that what he or she is trying to prove is more likely to be true than not true. This is sometimes referred to as "the burden of proof". (SB 2)

In example 12, "circumstantial evidence" is explained by offering a description which is followed by concrete examples. As Tiersma and Curtis (2008: 235) point out, "successful instructions on circumstantial evidence would emphasize the importance of strong as compared to weak evidence rather than attempting to educate jurors about the distinction between direct and circumstantial evidence".

[12] Some evidence proves a fact directly, such as testimony of a witness who saw a jet plane flying across the sky. Some evidence proves a fact indirectly, such as testimony of a witness who saw only the white trail that jet planes often leave. This indirect evidence is sometimes referred to as "circumstantial evidence." In either instance, the witness's testimony is evidence that a jet plane flew across the sky. (SB 3)

In Example 13, a definition and a description go together explaining an unknown word and an unknown phenomenon. A definition is followed by a description as it needs the help of a description to understand better. 
[13] While the term "good faith" has no precise definition, it means, among other things, an honest belief, a lack of malice, and the intent to perform all lawful obligations. A person who acts on a belief or on an opinion honestly held is not punishable under the law merely because that honest belief turns out to be incorrect or wrong. (SB 1)

Thus, the findings of the present study reveal that four main description structures are present in the corpus: (a) description + legal concept; (b) legal concept + description; (c) legal concept + definition + description; and (d) legal concept + description + exemplification. Table 3 presents the average distribution of these structures in the corpus. It should be therefore stated that explanatory procedures combine and overlap, always with the aim of presenting, in a simplified way, information that the jurors may find complex.

\begin{tabular}{|l|l|}
\hline TYPE OF DESCRIPTION & FREQUENCY OF OCCURRENCES, \% \\
\hline Description + legal concept & 34,5 \\
\hline Legal concept + description & 31,5 \\
\hline Legal concept + definition + description & 19 \\
\hline Legal concept + description + exemplification & 15 \\
\hline
\end{tabular}

Table 3. Distribution of the main description structures in the corpus

\subsubsection{Exemplification}

Exemplification is based on analogical and case-based processes and allows jurors "to focus on a more familiar experiential concept, which otherwise may remain expressed in abstract terms, and to link that concept to concrete and specific situations" (Anesa \& Fage-Butler, 2015: 123). In the type of interaction tackled in the corpus, the exemplification strategy is a resource lawyers frequently select to present legal knowledge by making it accessible to a lay audience, including jurors. This cognitive strategy is a form of formulation applied to the semantic-conceptual level of discourse. It includes the resources deployed by speakers to explain complex concepts in terms of everyday experience (Brünner, 1999; Ciapuscio, 2003), by providing factual examples of legal concepts with the aim of making these concepts less abstract, which therefore improves jurors' comprehension. Such examples are often easier to remember than general knowledge and hence are quite useful as an explanatory device in expert-lay interactions (Calsamiglia \& van Dijk, 2004).

In Example 14, the judge links the criminal law terms "actual possession" and "constructive possession" to concrete images of a badge and water bottles. This choice recalls jurors' possible personal experiences, a strategy that is fully in line with a comprehension improvement intent. 
[14] And you heard there was actual possession and constructive possession. You are in possession of the badge that's on you now. You have active control of that. These water bottles in front of you, you have constructive possession of them. You have control over them, but you do not have active control of them. It's not in your possession right now. (SB 1)

The judge describes the legal terms "actual possession" and "constructive possession" using simple icon images that can be easily visualized. Apart from conveying the specific features of the legal phenomena, the judge brings them closer to the juror's experience by means of the comparison with everyday objects that help to form mental pictures of the concepts. The judge feels necessary to ensure that legal concepts are understood by the jury and provides highly comprehensible explanations by epitomizing them in simple images that can be visualized. The following example illustrates the similar case.

[15] Direct evidence is simply evidence like the testimony of any eyewitness which, if you believe it, directly proves a fact. If a witness testified that he saw someone walking across a field and you believed him, that would be direct evidence that such a thing had happened (SB 2).

Here, the judge obviously considers the legal concept "direct evidence" opaque for the jury, and accordingly, explains by offering a definition followed by an example referring to down-to-earth and concrete events and objects. The judge does not give a "technical" definition; instead, he provides an example that helps the lay audience immediately understand the meaning of this legal concept, thus succeeding in improving its comprehensibility. Example 16 is also a case in point:

[16] "Taking" is when the defendant takes control of the victim's vehicle, even if the defendant does not force the victim to relinquish it. For example, forcibly removing a victim from a vehicle and placing him in the trunk would constitute taking the vehicle. (SB 3)

Here, the legal concept is 'taking' that is difficult to understand by a nonspecialized audience. Considering the appearance of a communication problem to be inevitable, the judge uses examples to improve clarity. The marker "for example" clearly shows the exemplification procedure.

Thus, examples refer to the act of presenting knowledge in a simpler way (Turnbull, 2018: 203-204). Since they provide incomplete information about legal issues, more precise definitions are needed in contexts requiring more detailed explanations.

\begin{tabular}{|l|l|}
\hline TYPE OF EXEMPLIFICATION STRUCTURES & FREQUENCY OF OCCURRENCES, $\%$ \\
\hline Scenario-based examples & 67 \\
\hline Object-based examples & 33 \\
\hline
\end{tabular}

Table 4. Distribution of the types of exemplification structures in the corpus 
The findings of the present study reveal that judges link legal concepts either to concrete objects (object-based examples) or to concrete events (scenario-based examples). The scenario-based exemplification strategy is selected when addressing the interlocutor directly to create a possible yet imaginary situation that allows them to explain a complex event (Ciapuscio, 2003). The average distribution of these types of exemplification is presented in Table 4.

\subsubsection{Metaphorization}

As a rhetorical strategy, metaphors help to keep the jury's attention. According to Bugliosi (1996), "it is not difficult to keep juror's attention for one, two, or even three days if the lawyer can deliver a powerful, exciting summation that is sprinkled with example, metaphor and humor". As a cognitive tool, metaphors establish links between two domains of experience, meaning or knowledge and determine how thought is structured and evolving (Lakoff, 1993: 202). As Lakoff and Johnson (2003: 10) point out, "in allowing us to focus on one aspect of a concept a metaphorical concept can keep us from focusing on other aspects of the concept that are inconsistent with that metaphor". Metaphorization offers a series of advantages, including the tangible quality of images from the physical world used to represent abstract and often complex concepts that would otherwise be difficult to define (Gotti, 2008). This is especially true in the case of legal-lay interactions, where a number of concepts are defined and explained in terms of linguistic metaphors. What follows is an example from the corpus where an abstract concept ("hard evidence") is explained by means of metaphors:

[17] You will see it's little more than a river or a stream. You have seen a mountain or ocean of evidence. (SB 3)

The comparison with everyday objects ("river", "stream", "mountain", "ocean") makes it possible to grasp the abstract legal concept. The metaphorization allows the judge to explain, in a simplified fashion, how evidence will be presented by the attorneys. As distinct from definitions and descriptions, the use of metaphors and examples is directed at ensuring the jury's comprehension by bringing the legal information closer to their everyday experience through the mention of objects or events typical of everyday life.

Overall, the results of the present study confirm that strategies employed by judges with the aim of explaining legal knowledge to a lay audience and prevent the emergence of communicative problems are:

(1) definition, selected to explain technical terms in a paradigmatic manner;

(2) description, employed to communicate new knowledge by relating it to the old one in a narrative way; 
(3) exemplification, used with the intention to avoid communication problems by referring complex legal concepts to concrete objects or events;

(4) metaphorization, which ensures the jury's comprehension by bringing the legal information (domain 1) closer to their everyday experience (domain 2).

The quantitative analysis of the explanatory strategies shows that definitions and descriptions, comprising respectively $40 \%$ and $29 \%$ of all strategies found in the corpus, are the most commonly used explanatory strategies, while examples and metaphors are the least commonly used tools comprising respectively $21 \%$ and $10 \%$ of all explanatory strategies used (see Table 5). This difference is partly due to the fact that metaphors make meanings more ambiguous than clear (Krapivkina, 2017), and exemplifications provide only incomplete information about legal topics. What is more, as Baguley et al. (2017: 7) point out, "providing factual examples of legal concepts reduces the conceptual complexity, but also increases the amount of information. This increase in the amount of information may then negate the effect of reducing the conceptual complexity".

\begin{tabular}{|l|l|}
\hline EXPLANATORY TOOLS & FREQUENCY OF OCCURRENCES, \% \\
\hline Definitions & 40 \\
\hline Descriptions & 29 \\
\hline Examples & 21 \\
\hline Metaphors & 10 \\
\hline
\end{tabular}

Table 5. Frequency of occurrences of explanatory strategies in the corpus

\subsection{Comprehensibility experiment and survey}

In order to ensure the validity of conclusions, the analysis presented in subsection 4.1. was combined with the experimental research. Charrow and Charrow's (1979) experimental method was applied to reveal the accuracy of comprehension of jury instructions before and after employing the explanatory strategies. Two jury instructions were recorded and played twice to each of 44 participants, who were not provided with written copies of the instructions. They were asked to paraphrase the segments of the instructions which contained the legal concepts "preponderance of evidence" and "circumstantial evidence". Through the analysis of these paraphrases, it was revealed that no participant was able to accurately paraphrase all the segments. Moreover, they were able to remember and paraphrase less than half of the material they had heard.

Table 6 shows the percentage of explanations of the legal concepts "preponderance of evidence" and "circumstantial evidence" provided by the participants. Not surprisingly, only $24 \%$ of the participants accurately paraphrased the sentences containing the concept "circumstantial evidence" ("indirect 
evidence"). Two participants (5\%) correctly described the concept "preponderance of evidence" as evidence which proves that it is more likely than not that the facts presented are true.

\begin{tabular}{|l|l|l|l|}
\hline \multicolumn{2}{|c|}{$\begin{array}{c}\text { EXPLANATIONS OF THE LEGAL TERM } \\
\text { "circumstantial evidence" }\end{array}$} & \multicolumn{2}{c|}{$\begin{array}{c}\text { EXPLANATIONS OF THE LEGAL TERM } \\
\text { "preponderance of evidence" }\end{array}$} \\
\hline Explanation & $\%$ & Explanation & $\%$ \\
\hline indirect evidence & 24 & advantage of the evidence & 44 \\
\hline circumstance-dependent & 19 & reasonable doubt & 31 \\
\hline less reliable evidence & 18 & strong evidence & 14 \\
\hline detailed information & 17 & $\begin{array}{l}\text { slow pondering of } \\
\text { evidence }\end{array}$ & 6 \\
\hline weak evidence & 14 & more convincing evidence & 5 \\
\hline hearsay & 8 & & \\
\hline
\end{tabular}

Table 6. Interpretations of "preponderance of evidence" and "circumstantial evidence" provided by the survey participants

As the second phase of the experimental research, paraphrasing difficulties were identified. A comprehension difficulty research survey was used with the intention to better understand linguistic features of jury instructions which make them difficult to process. The survey included two questions used to identify troublesome lexical and syntactic features. The answers to these questions had already been supplied, and the participants had been able to opt for more than one answer (see Appendix). Table 7 presents the list of these linguistic features and the percentage of participants who selected them.

\begin{tabular}{|l|l|}
\hline TROUBLESOME LINGUISTIC FEATURES & $\begin{array}{c}\text { \% OF PARTICIPANTS WHO SELECTED } \\
\text { THE DIFFICULTY }\end{array}$ \\
\hline \multicolumn{1}{|c|}{ Syntactic difficulties } \\
\hline long sentences & 58 \\
\hline complicated sentence structures & 46 \\
\hline word order & 34 \\
\hline passive sentences Lexical and semantic & 35 \\
\hline \multicolumn{2}{|c|}{ difficulties } \\
\hline unfamiliar legal terms & 94 \\
\hline archaic words & 29 \\
\hline abstract words & 68 \\
\hline nominalizations & 54 \\
\hline $\begin{array}{l}\text { differences between legal and ordinary } \\
\text { concepts }\end{array}$ & 44 \\
\hline
\end{tabular}

Table 7. Troublesome lexical and syntactic features of jury instructions 
The survey results show that misunderstandings mainly arise from layperson's unfamiliarity with legal concepts and their abstract nature and, to a lesser extent, from the complicated syntactic characteristics of legalese. When unfamiliar terms were replaced with the common words or exemplified, the comprehensibility of instructions improved, and the number of participants who accurately interpreted the fragments of the instructions containing the legal terms "preponderance of evidence" and "circumstantial evidence" increased by $34 \%$ and $47 \%$ respectively. The results obtained are due both to the simpler phrasing and to the fact that the participants were provided with examples.

\section{PEDAGOGICAL IMPLICATIONS}

While our understanding of courtroom-based discursive practices has been enhanced by findings on the main explanatory strategies used in jury instructions and the comprehension difficulties experienced by a lay audience, it is necessary to look into how our results have relevant pedagogical implications. The findings of the present study can serve as a basis for course and materials design, in the preparation of instructional materials intended for law students in Legal English courses, who should be able to interact with laypeople in the legal setting. The ESP instructors are required to provide the students with guidance on how to use explanatory strategies when interacting with clients. After the students have been acquainted with the most common explanatory strategies, attention can be directed to their complex use in rewriting legal texts to promote readability to a lay audience, the use of verbs introducing definitions, as well as the role of metaphors and synonymic expressions as alternative terms for elusive legal concepts. It is recommended that ESP instructors use paraphrasing exercises and synonym-focused exercises that develop one of the most important reformulation skills. The students should be encouraged to replace legal concepts in the original text with the common words, while retaining the original meaning. When explaining a complicated topic, it is helpful to illustrate a point by providing examples. These recommendations for practical applications can be used in exercises to expose the law students to semantic and pragmatic choices that are adopted when preparing legal texts addressed to clients; this familiarizes them with the language resources necessary for legal-lay interactions. Three activity types are presented below to demonstrate how the findings of the present study can be turned into classroom activities for ESP pedagogy. Their overall goal is to develop the learners' ability to restate the meaning of legal concepts using common words or examples.

Task 1: Study the extract from the legal text and replace the legal concepts written in bold with the common words. 
The government must prove each element of the crime charged to each and every one of you beyond a reasonable doubt. If the government fails to prove an element beyond a reasonable doubt, then you must find that that element has not been proven and find the defendant not guilty. While the government's burden of proof is a strict and heavy burden, it is not necessary that it be proved beyond all possible doubt. It is only required that the government's proof exclude any reasonable doubt concerning that element.

Task 2: Study the extract from the legal text and illustrate the meaning of the legal concepts written in bold with the examples.

Evidence consists of testimony, writings, material objects or other things presented to the senses and offered to prove whether a fact exists or does not exist. Evidence is either direct or circumstantial. Direct evidence is evidence that directly proves a fact. It is evidence which by itself, if found to be true, establishes that fact. Circumstantial evidence is evidence that, if found to be true, proves a fact from which an inference of the existence of another fact may be drawn. A factual inference is a deduction that may logically and reasonably be drawn from one or more facts established by the evidence.

Task 3: Study the sentences taken from a legal text and find the synonyms of the words written in bold.

(1) First, that the defendant knowingly and willfully falsified, concealed, or covered up a fact.

(2) The government must prove a causal link between the defendant's false statement and the application for or receipt of more than $\$ 1,000.00$ in benefits.

(3) The government must prove an effect on commerce.

(4) This case involves claims of negligence.

(5) Reckless conduct reflects a knowing disregard of a substantial and unjustifiable risk.

\section{CONCLUSION}

This article's significance lies in the attempt to describe the explanatory strategies intended to improve the comprehensibility of jury instructions and overcome communication problems in the legal setting. It contributes to the knowledge of the ways of accommodating professional discursive practices towards a lay audience and draws attention to the issues of knowledge asymmetries. Twentyseven pattern jury instructions drawn from the US court websites were analyzed with the aim to identify the most common explanatory strategies employed to translate complex legal concepts into the terms of everyday life. Since they are basically tools for facilitating access to complex legal information, their function is to aid the layperson's comprehension. These strategies, namely definition, description, exemplification, and metaphorization, have specific features that allow us to distinguish between them. Among the most common explanatory strategies employed in pattern jury instructions, a high incidence of definitions and descriptions was observed. According to the corpus-based analysis, they seem to be typical of the discourse type that was the focus of the present study. As confirmed by the empirical data, examples and metaphors are less frequent 
strategies used to enhance verbalization of abstract legal knowledge in a simplified manner and facilitate comprehension of jury instructions by jurors. Given that professionals and laymen have very different "input values" in terms of language, knowledge, status, and power, one might expect a convergence because of the idea that efforts are made to decrease the gap between communicants and improve the efficiency in the courtroom. In the experiment conducted, the explanatory strategies have improved the comprehensibility of jury instructions. The findings of the present study showed that misunderstandings mainly arise from layperson's unfamiliarity with legal concepts and their elusive nature and, to a lesser extent, from the complicated syntactic characteristics of legalese. When unfamiliar terms were replaced with the common words, the comprehensibility of instructions improved, and the number of participants who accurately interpreted the fragments of the jury instructions increased.

This study is only a glimpse into asymmetrical interactions in the legal setting. We suggest that further studies be undertaken to explore this area of research, either by extending the methodology or examining other aspects of legallay interactions, including but not limited to the types of syntactic complexity that interfere with comprehension. This article will hopefully encourage researchers and practitioners to explore explanatory strategies employed by judges in other legal systems and compare their results with the ones obtained in this research. In addition, the findings of the present study refer to jury instructions and, consequently, a limitation of the analysis is its exclusive focus on written courtroom discourse. Further research is thus needed into oral legal-lay interactions in various legal settings in order to complement findings of the present study with the distinctive characteristics of the spoken legal-lay discourse.

[Paper submitted 12 May 2020]

[Revised version received 13 Aug 2020]

[Revised version accepted for publication 20 Aug 2020]

\section{Acknowledgement}

I would like to thank Professor Nadežda Silaški and two anonymous reviewers for their insightful comments and useful suggestions that helped to improve the manuscript.

\section{References}

Anesa, P. (2009). "Now you are getting into the law": Mediation of specialized language in a jury trial. Fachsprache, 31(1-2), 64-82. https://doi.org/10.24989/fs.v31i1-2.1426

Anesa, P. (2012). Jury trials and the popularization of legal language: A discourse analytical approach. Bern: Peter Lang. https://doi.org/10.3726/978-3-0351-0457-8 
Anesa, P. (2016). The deconstruction and reconstruction of legal information in expertlay online interaction. ESP Today, 4(1), 69-86. Retrieved from http://www.esptodayjournal.org/pdf/current_issue/3.6.2016/PATRIZIA\%20ANES A-full\%20text.pdf

Anesa, P., \& Fage-Butler, A. (2015). Popularizing biomedical information on an online health forum. Ibérica, 29, 105-128.

Baguley, C. M., McKimmie, B. M., \& Masser, B. M. (2017). Deconstructing the simplification of jury instructions: How simplifying the features of complexity affects jurors' application of instructions. Law and Human Behavior, 41(3), 284-304. https://psycnet.apa.org/doi/10.1037/lhb0000234

Baguley, C. M., McKimmie, B. M., \& Masser, B. M. (2019). Re-evaluating how to measure jurors' comprehension and application of jury instructions. Psychology, Crime \& Law, 26(1), 53-66. https://doi.org/10.1080/1068316X.2019.1634195

Bruner, J. (1991). The narrative construction of reality. Critical Inquiry, 18(1), 1-21.

Brünner, G. (1999). Medientypische Aspekte der Kommunikation in medizinischen Fernsehsendungen [Media-typical aspects of communication in medical TV programs]. In K. Bührig, \& Y. Matras (Eds.), Sprachtheorie und sprachliches Handeln (pp. 25-42). Tübingen: Stauffenburg-Verlag.

Buchanan, R. W., Pryor, B., Taylor, K. P., \& Strawn, D. U. (1978). Legal communication: An investigation of juror comprehension of pattern instructions. Communication Quarterly, 26, 31-35.

Bugliosi, V. (1996). Outrage: The five reasons why O. J. Simpson got away with murder. New York: Island Books.

Cacchiani, S. (2018). Webpage usability and utility content: Citizens' rights and the law on gov.uk. Iperstoria, 2018(12), 192-205.

Calsamiglia, H., \& van Dijk, T. A. (2004). Popularization discourse and knowledge about the genome. Discourse \& Society, 15(4), 369-389. https://doi.org/10.1177\%2F0957926504043705

Charrow, R., \& Charrow, V. (1979). Making legal language understandable: A psycholinguistic study of jury instructions. Columbia Law Review, 79, 1306-1400.

Ciapuscio, G. E. (2003). Formulation and reformulation procedures in verbal interactions between experts and (semi-)laypersons. Discourse Studies, 5(2), 207-233. https://doi.org/10.1177/1461445603005002004

Diamond, S. S., \& Levi, J. N. (1996). Improving decisions on death by revising and testing jury instructions. Judicature, 79, 224-232.

Elwork, A., Sales, B. D., \& Alfini, J. J. (1977). Juridic decisions: In ignorance of the law or in light of it? Law and Human Behavior, 1(2), 163-189. https://psycnet.apa.org/doi/10.1007/BF01053437

Frank, J., \& Applegate, B. K. (1998). Assessing juror understanding of capital-sentencing instructions. Crime \& Delinquency, 44(3), 412-433. https://psycnetapa.org/doi/10.1177/0011128798044003005

Gotti, M. (2008). Investigating specialized discourse. Bern: Peter Lang. https://doi.org/10.3726/978-3-0351-0214-7

Gotti, M. (2014). Reformulation and recontextualization in popularization discourse. Ibérica, 27, 15-34.

Heffer, C. (2005). The language of jury trial: A corpus-aided analysis of legal-lay discourse. Houndmills: Palgrave Macmillan.

Imwinkeiried, E. J., \& Schwed, L. R. (1987). Guidelines for drafting understandable jury instructions: An introduction to the use of psycholinguistics. Criminal Law Bulletin, 23, 135-150. 
Krapivkina, O. A. (2017). Expert-lay interaction in jury trials (case study of closing arguments). Journal of Language and Cultural Education, 5(3), 77-92. https://doi.org/10.1515/jolace-2017-0029

Krapivkina, O., Kolesnikova, K., Borisovskaya, I., \& Taranova, E. (2019). Addressee as a key factor of courtroom discourse production. SHS Web of Conferences, 69, 1-5. https://doi.org/10.1051/shsconf/20196900068

Lakoff, G. (1993). The contemporary theory of metaphor. In A. Ortony (Ed.), Metaphor and thought (pp. 202-251). Cambridge: Cambridge University Press. https://doi.org/10.1017/CB09781139173865

Lakoff, G., \& Johnson, M. (2003). Metaphors we live by. Chicago: Chicago University Press.

Lieberman, J. (2009). The psychology of the jury instruction process. In J. D. Lieberman, \& D. A. Krauss (Eds.), Jury psychology: Social aspects of trial processes: Psychology in the courtroom, Vol. 1 (pp. 129-155). Burlington, VT: Ashgate Publishing Limited.

McCarthy, N. (2003, July). Plain English instructions are coming to juries. California Bar Journal. Retrieved from

http://archive.calbar.ca.gov/archive/Archive.aspx?articleId=50838\&categoryId=50 836\&month=7\&year=2003

Nickerson, R. S. (1999). How we know - and sometimes misjudge - what others know: Imputing one's own knowledge to others. Psychological Bulletin, 125(6), 737-759. https://doi.org/10.1037/0033-2909.125.6.737

Roelcke, T. (2018). Rechtssprachliche Kommunikation. Eine Typologie [Legal communication: A typology]. In J. Engberg, K. Luttermann, S. Cacchiani, \& C. Preite (Eds.), Popularization and knowledge mediation in the law. Popularisierung und Wissensvermittlung im Recht (pp. 3-28). Zürich: Lit Verlag.

Rose, G. V., \& Ogloff, J. (2001). Evaluating the comprehensibility of jury instructions: A method and an example. Law and Human Behavior, 25(4), 409-431. https://doi.org/10.1023/A:1010659703309

Tiersma, P. (1999). Legal language. Chicago, IL: University of Chicago Press.

Tiersma, P. (2010). Redrafting California's jury instructions. In M. Coulthard, \& A. Johnson (Eds.), The Routledge handbook of forensic linguistics (pp. 251-264). London: Routledge.

Tiersma, P., \& Curtis, M. (2008). Testing the comprehensibility of jury instructions: California's old and new instructions on circumstantial evidence. Journal of Court Innovation, 1, 231-264.

Turnbull, J. (2018). Communicating and recontextualizing legal advice online in English. In J. Engberg, K. Luttermann, S. Cacchiani, \& C. Preite (Eds.), Popularization and knowledge mediation in the law. Popularisierung und Wissensvermittlung im Recht (pp. 201-222). Zürich: Lit Verlag.

Wiener, R. L., Pritchard, C. C., \& Weston, M. (1995). Comprehensibility of approved jury instructions in capital murder cases. Journal of Applied Psychology, 80(4), 455-467. https://doi.org/10.1037/0021-9010.80.4.455

Zethsen, K. K. (2009). Intralingual translation: An attempt at description. Meta, 54(4), 795812. https://doi.org/10.7202/038904ar 
OLGA BOGINSKAYA holds a PhD in Philology. She is Associate Professor at Irkutsk National Research Technical University. Her research interests lie in the area of legal discourse. Her current projects focus on the studies of explanatory strategies in legal discourse.

\section{Appendix}

\section{Comprehension difficulty research survey questions}

1. Select syntactic difficulties which hinder comprehension of jury instructions

\section{Olong sentences}

Ocomplicated sentence structures

Oword order

Opassive sentences

2. Select lexical and semantic difficulties which hinder comprehension of jury instructions

Ounfamiliar legal terms

Oarchaic words

Oabstract words

Onominalizations

Odifferences between legal and ordinary concepts 